Article

\title{
Grounding System Modeling and Evaluation Using Integrated Circuit Based Fast Relaxed Vector Fitting Approach, Considering Soil Ionization
}

\author{
Maziyar Fakhraei ${ }^{1}$, Mehrdad Mahmoudian ${ }^{2, *}$ and Eduardo Manuel Godinho Rodrigues ${ }^{3, * \text { (D) }}$ \\ 1 Department of Control, Fars Regional Electric Company, Shiraz 71346, Iran; M.fakhraie@sutech.ac.ir \\ 2 Electrical Engineering Department, Firouzabad Institute of Higher Education, Firouzabad 74717, Iran \\ 3 School of Design, University of Aveiro, Management and Production Technologies of Northern \\ Aveiro (ESAN), 3720-509 Oliveira de Azeméis, Portugal \\ * Correspondence: mahmoodian.cc@fabad-ihe.ac.ir (M.M.); emgrodrigues@ua.pt (E.M.G.R.)
}

Received: 16 June 2020; Accepted: 7 August 2020; Published: 14 August 2020

\begin{abstract}
Since high voltage transmission line towers or wind turbines structures are installed in high-altitude areas, it is essential to achieve a high overvoltage protection system against direct and indirect lightning strikes collisions. The lightning current must be discharged quickly into the protective earth, to prevent the dangerous over-voltages formation and define a reference voltage node. This paper presents a novel model to assess the behavior of the grounding system, based on Pocklington integral equations under lightning magnetic fields and variations in soil ionization, in which an explicit circuit-based vector fitting RLC admittance branches are proposed. The frequency-dependent behavior of grounding system frequency response and soil ionization effect is modeled in time domain, straightly to implement into the electro-magnetic transient program (EMTP). The model verification contains horizontal, vertical, and their combinations of grounding grids to represent the complete investigations under lightning strikes. The harmonic impedance mathematical formulations and principles are derived based on a rational function, that could be applicable on ground potential rise (GPR) investigation.
\end{abstract}

Keywords: grounding system; lightning stroke; soil ionization; vector fitting

\section{Introduction}

Grounding systems, or the buried electrodes under the soil (either individually or in combination and interconnected with regular arrangements), are essential and significant to provide the health and safety for the staff occupied at high-voltage substations, power plants and industrial areas. The main purpose of grounding systems is to prevent unauthorized step voltage and touch voltage that faces human health at risk. Their other task is to provide the same common reference potential for all electrical and electronic components, especially protective equipment connected to the power grid. In almost a few years, the development and installation of impeccable lightning protection system for high voltage towers and wind turbine structures, due to their high altitudes and vulnerability to potential lightning strikes, has become one of the fields of interest and study for researchers [1,2].

In all types of electrical grounding systems, these two requirements have to be considered: (1) to provide the safety and health for the people who are in contact with electrical equipment; (2) to help to maintain the integrity of electrical equipment and increase their toughness to ensure performance, regardless of safety issues [3,4]. In the first view, the principle of safety is for people in the community who are the end consumers of electrical energy, to prevent firing, equipment short circuit (SC) breakdown, and to stopover SC current. This kind of strategy is called protective earth, 
which is utilized to connect the electrical equipment bodies to a neutral reference node. Consequently, it could decrease the touch and step voltages during or after a contingency, such as a fault occurrence or lightning strokes inside the substation or its proximity. In the second perspective, the principle is to maintain insulation and to ensure the safety of electrical equipment. Then, in order to protect the equipment insulation and the movement of the traveling waves due to the lightning strike and the switching in the transmission system of power, there must be a parallel path to a reliable grounding system, to discharge these currents with very low impedance [5]. Since the ground impedance of the grounding grid is considerable, it will prevent rapid discharge and cause a hypothetically dangerous local potential at the point of lightning evacuation and increase ground potential rise (GPR) [6,7].

The transient behavior of grounding systems directly and significantly affects the performance of the electrical system under SC fault conditions or lightning strike collisions [8]. Due to the fact that most power network modeling to analyze the electromagnetic transient situations in software packages such as electro-magnetic transient program (EMTP) are in lumped circuits, the lack of a proper method with the precision that can provide this criterion has led to modelling the grounding grids with simple passive RLC parameters. There are some investigations to use the models presented in [9-12], such as circuit theory and distributed transmission lines. In recent years, the researchers have been trying to provide a suitable model for grounding systems that also behave appropriately in electromagnetic transient states. However, these studies have usually succeeded in providing models that are either usable at low frequencies or should be considered a constant classification for all grounding grids [13,14].

Thoroughly, various modeling approaches have been presented so far, which, based on numerical methods, investigate the behavior of the grounding systems at high frequencies. For instance, to implement and simulate the grounding system into an alternative transient program (ATP), a simple circuit based model is proposed by Ramamurti et al. in [15]. In this technique, after dividing the earth into $n$ pieces, each component is modeled with an equivalent circuit with lumped elements, including self-inductance (M) and mutual inductances (L) and earth leakage conductance (G). The analysis based on electromagnetic fields is the most complicated method to model the high-frequency behavior of the grounding grids, because Maxwell's equations should be solved with the least assumptions and initializations [16-19]. Therefore, by solving the Maxwell equations, it is possible to calculate the electromagnetic fields at any points of the electrodes, and then, the values of voltage and current can be calculated without approximation. Grcev in [18-20] has presented this strategy for the first time, in which the potential in different locations will be measurable on the surface of the conductors into the Earth. Then, the inverse fast Fourier transform (IFFT) tool was used to calculate the grounding system parameters in the time domain. However, the IFFT tool is approximated due to the dependence on the appropriate window selection for a sequential sampling of the signal (in the frequency domain). Moreover, the observance of the distance between sampling steps is necessary, in accordance with the Nyquist law, results in a large volume of specimens in the frequency domain samples that are required to achieve the time domain parameters [21]. Another problem is that it needs to be corrected at low sampling frequencies, and it cannot be used with an inverse Fourier transform directly. Since the theory of the electromagnetic field is based on the method of moments (MoM), and solving Maxwell's equations and has minimum assumptions, it has a high accuracy to determine the grounding grid variables. Nonetheless, this model is very challenging and, as a result, for large networks, the calculation time will be dramatically increased [22]. Another method is also used to model the grounding system, which is known as the hybrid method [23-25], combined with the electromagnetic field theory and circuit concept. In these procedures, the main and leakage currents are involved in the calculations jointly. They use the quasi-static approximation and reflexive coefficients to solve the problem, in order to consider the air-ground intermediate effect [26]. In the hybrid technique to model the entire grounding rods, they are divided into $n$ small part, and then the electric field is calculated at each point using the Maxwell equations. The solutions obtained are used to calculate the inductive, capacitive, and resistive components within the framework of theoretical circuit methods to increase 
the accuracy of computations. In some literature, the circuit-based models have been proposed without considering the effect of soil ionization, or some negative resistance parameters have been calculated which are physically unacceptable $[27,28]$.

In high frequency analysis, the soil ionization causes non-linearization of the transient behavior of the buried grounding system in the Earth. Currently, if these equipments are buried in multilayer soils with different special resistances and with different geometries such as cylindrical or spherical soils, the modeling of its electrodes, in order to analyze power networks in software packages, is practically impossible. Therefore, this paper presents a novel technique to investigate all these phenomena, in order to investigate the electromagnetic transient states of lightning strikes by fast relaxed vector fitting (FRVF) algorithm. Using this method, each arbitrary grounding system can be implemented and evaluated with just a few simple RLC admittance branches with a low-order state-space transfer function and frequency response in a very wide frequency range. Another feature of this process is its high precision and computational speed.

\section{Problem Formulation}

When the lightning strikes collide to a transmission line tower, the current flows to the grounding grid directly. The Maxwell equations integrated with Pocklington equations can model the lightning current flowed to any grounding electrodes or rods [29,30]. These sets of Pocklington-Maxwell equations will be solved and evaluate the high-frequency grounding grid behaviors. The excitation function $\left(E_{\mathrm{sm}}^{\mathrm{exc}}(\mathrm{s})\right)$ in the loss-full medium is derived by the following equation.

$$
\begin{aligned}
E_{\mathrm{sm}}^{\mathrm{exc}}(\mathrm{s})= & \mathrm{C} \times \sum_{\mathrm{n}=1}^{\mathrm{N}_{W}}\left\{\int_{C_{\mathrm{n}}} \mathrm{I}_{\mathrm{n}}\left(\mathrm{s}^{\prime}\right) \times \hat{\mathrm{s}_{\mathrm{m}}} \times \hat{\mathrm{s}_{\mathrm{n}}^{\prime}} \times\left[\mathrm{k}_{1}^{2}+\nabla \nabla\right] \mathrm{g}_{\mathrm{on}}\left(\mathrm{s}_{\mathrm{m}}, \mathrm{s}_{\mathrm{n}}^{\prime}\right) \times \mathrm{ds^{ \prime }}\right. \\
& +\mathrm{R} \times \int_{C_{\mathrm{n}}} \mathrm{I}\left(\mathrm{s}_{\mathrm{n}}^{\prime}\right) \mathrm{s}_{\mathrm{m}} \times \hat{\mathrm{s}_{\mathrm{n}}^{*}} \times\left[\mathrm{k}_{1}^{2}+\nabla \nabla\right] \mathrm{g}_{\mathrm{on}}\left(\mathrm{s}_{\mathrm{m}}, \mathrm{s}_{\mathrm{n}}^{*}\right) \times \mathrm{ds^{ \prime }} \\
& +\int_{\mathrm{C}_{\mathrm{n}}^{\prime}} \mathrm{I}_{\mathrm{n}}\left(\mathrm{s}^{\prime}\right) \times \hat{\mathrm{s}_{\mathrm{m}}} \times \overrightarrow{\mathrm{G}}_{\mathrm{s}}\left(\mathrm{s}_{\mathrm{m}}, \mathrm{s}_{\mathrm{n}}^{\prime}\right) \times \mathrm{ds^{ \prime } \}}
\end{aligned}
$$

where,

$$
\begin{gathered}
\mathrm{m}=1,2, \ldots, \mathrm{N}_{\mathrm{W}} \\
\mathrm{C}=-\frac{1}{\mathrm{j} 4 \pi \omega \epsilon_{\text {efec }}} ; \mathrm{R}=\frac{\mathrm{k}_{0}^{2}-\mathrm{k}_{1}^{2}}{\mathrm{k}^{2}+\mathrm{k}_{1}^{2}}
\end{gathered}
$$

$\mathrm{I}_{\mathrm{n}}\left(\mathrm{s}^{\prime}\right)$ is the current induced along a horizontal electrode and a vertical rod as shown in Figure 1, and $g_{o}\left(s, s^{\prime}\right)$ represents the half-power green function, while the $g_{i}\left(s, s^{\prime}\right)$ increases according to image theory. Thus, they are found by (3) and (4).

$$
\begin{aligned}
& \mathrm{g}_{0}\left(\mathrm{~s}, \mathrm{~s}^{\prime}\right)=\frac{\mathrm{e}^{-\mathrm{j} \mathrm{k}_{1} \mathrm{R}_{0}}}{\mathrm{R}_{0}} \\
& \mathrm{~g}_{0}\left(\mathrm{~s}, \mathrm{~s}^{*}\right)=\frac{\mathrm{e}^{-\mathrm{j} \mathrm{k}_{1} \mathrm{R}_{1}}}{\mathrm{R}_{1}}
\end{aligned}
$$

where $R_{0}$ and $R_{1}$ are the distance between the reference point and the image point to the observer. Furthermore, $\mathrm{k}_{0}$ and $\mathrm{k}_{1}$ represent the propagation constant in air and loss-full ground, respectively, in which they are defined with the following formulations.

$$
\begin{gathered}
\mathrm{k}_{0}^{2}=\omega^{2} \mu_{0} \epsilon_{0} \\
\mathrm{k}_{1}^{2}=\omega^{2} \mu_{0} \epsilon_{\text {eff }}=\omega^{2} \mu_{0}\left(\epsilon_{0} \epsilon_{\mathrm{r}}-\mathrm{j} \frac{\sigma}{\omega}\right)
\end{gathered}
$$


where $\epsilon_{\mathrm{r}}$ and $\sigma$ are Earth permeability and conductivity coefficients. Since $\omega=2 \pi \mathrm{f}$ represents the angular frequency, the $\vec{G}_{s}\left(s, s^{\prime}\right)$ could be extracted through electric dipoles using Sumerfeld integral law.

$$
\vec{G}_{s}\left(s, s^{\prime}\right)=\left(\hat{x} \cdot \hat{s}^{\prime}\right) \times\left(G_{\rho}^{\mathrm{H}} \cdot \vec{\rho}+G_{\varphi}^{\mathrm{H}} \cdot \vec{\varphi}+G_{z}^{\mathrm{H}} \cdot \vec{z}\right)+\left(\hat{z} \cdot \hat{s}^{\prime}\right) \times\left(G_{\rho}^{\mathrm{V}} \cdot \vec{\rho}+G_{z}^{\mathrm{V}} \cdot \vec{z}\right)
$$

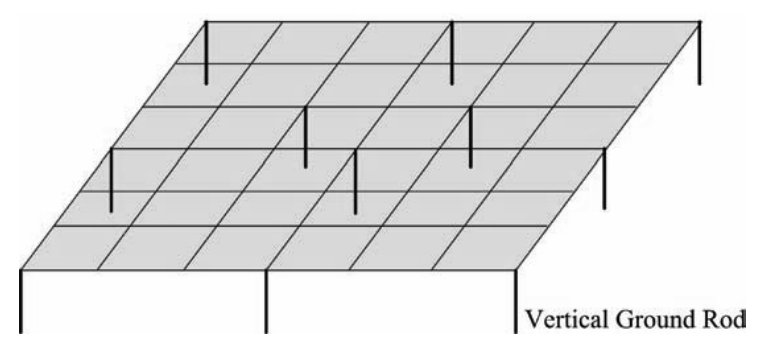

(a)
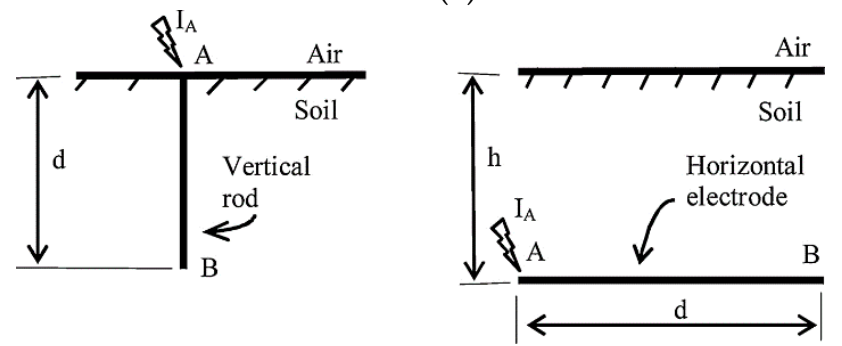

(b)

Figure 1. (a) A typical grounding grid, (b) schematic view of a horizontal electrode and a vertical rod.

The unknown current $I_{n}^{\mathrm{e}}(\vartheta)$ flowing in nth section of the grounding grid, can be approximated by the sum of finite and linear independent vectors $f_{n i}$ with weight coefficients as (8).

$$
\mathrm{I}_{\mathrm{n}}^{\mathrm{e}}\left(\mathrm{s}^{\prime}\right)=\sum_{=1}^{\mathrm{n}} \mathrm{I}_{\mathrm{ni}} \mathrm{f}_{\mathrm{ni}}\left(\mathrm{s}^{\prime}\right)=\{\mathrm{f}\}_{\mathrm{n}}^{\mathrm{T}}\{\mathrm{I}\}_{\mathrm{n}}
$$

where the iso-parametric variables result in:

$$
\mathrm{I}_{\mathrm{n}}^{\mathrm{e}}(\vartheta)=\sum_{\mathrm{i}=1}^{\mathrm{n}} \mathrm{I}_{\mathrm{ni}} \mathrm{f}_{\mathrm{ni}}(\vartheta)=\left\{\mathrm{f}_{\mathrm{n}}^{\mathrm{T}}\{\mathrm{I}\}_{\mathrm{n}}\right.
$$

Using the equations written in (10) will give us a proper linearization and approximation at border elements.

$$
\mathrm{f}_{1}=\frac{1-\vartheta}{2} ; \mathrm{f}_{2}=1-\mathrm{f}_{1}
$$

Then, the impedance matrix is calculated in (11).

$$
\begin{aligned}
& {[Z]_{j i}=-\int_{-1}^{1} \int_{-1}^{1}\{D\}_{j}\left[D^{\prime}\right\}_{i}^{T} g_{o, n m}\left(s_{m}, s_{n}^{\prime}\right) \frac{d s_{n}}{d \vartheta^{\prime}} d \vartheta^{\prime} \times \frac{d s_{m}}{d \vartheta} d \vartheta} \\
& +\mathrm{k}_{1}^{2} \times \hat{\mathrm{s}_{\mathrm{m}}} \times \hat{\mathrm{s}_{\mathrm{n}}^{\prime}} \times \int_{-1}^{1} \int_{-1}^{1}\{\mathrm{f}\}_{\mathrm{j}}\left\{\mathrm{f}^{\prime}\right\}_{\mathrm{i}}^{\mathrm{T}} \times \mathrm{g}_{\mathrm{o}, \mathrm{nm}}\left(\mathrm{s}_{\mathrm{m}}, \mathrm{s}_{\mathrm{n}}^{\prime}\right) \frac{\mathrm{ds_{ \textrm {n } }}}{\mathrm{d} \vartheta^{\prime}} \mathrm{d} \vartheta^{\prime} \times \frac{\mathrm{d} \mathrm{s}_{\mathrm{m}}}{\mathrm{d} \vartheta} \mathrm{d} \vartheta \\
& -\mathrm{R} \times \int_{-1}^{1} \int_{-1}^{1}\{D\}_{j}\left\{D^{\prime}\right\}_{i}^{T} g_{i, n m}\left(s_{m}, s_{n}^{*}\right) \frac{d s_{n}}{d \vartheta^{\prime}} d \vartheta^{\prime} \times \frac{d s_{m}}{d \vartheta} d \vartheta \\
& + \text { R. } k_{1}^{2} \times \mathrm{s}_{\mathrm{m}} \times \mathrm{s}_{\mathrm{n}}^{*} \times \int_{-1}^{1} \int_{-1}^{1}\{\mathrm{f}\}_{j}\left\{\mathrm{f}^{\prime}\right\}_{\mathrm{i}}^{\mathrm{T}} \times \mathrm{g}_{\mathrm{i}, \mathrm{nm}}\left(\mathrm{s}_{\mathrm{m}}, \mathrm{s}_{\mathrm{n}}^{*}\right) \frac{\mathrm{d} \mathrm{s}_{\mathrm{n}}}{\mathrm{d} \vartheta^{\prime}} \mathrm{d} \vartheta^{\prime} \times \frac{\mathrm{d} \mathrm{s}_{\mathrm{m}}}{\mathrm{d} \vartheta} \mathrm{d} \vartheta \\
& +\hat{s_{\mathrm{m}}} \times \int_{-1}^{1} \int_{-1}^{1}\left\{\mathrm{f}_{\mathrm{j}}\left\{\mathrm{f}^{\prime}\right\}_{\mathrm{i}}^{\mathrm{T}} \times \overrightarrow{\mathrm{G}}_{\mathrm{s}, \mathrm{nm}}\left(\mathrm{s}_{\mathrm{m}}, \mathrm{s}_{\mathrm{n}}^{\prime}\right) \frac{\mathrm{d} \mathrm{s}_{\mathrm{n}}}{\mathrm{d} \vartheta^{\prime}} \mathrm{d} \vartheta^{\prime} \times \frac{\mathrm{d} \mathrm{s}_{\mathrm{m}}}{\mathrm{d} \vartheta} \mathrm{d} \vartheta\right.
\end{aligned}
$$


The matrixes $\{f\}$ and $\left\{f^{\prime}\right\}$ consist of image functions, while $\{D\}$ and $\left\{D^{\prime}\right\}$ represent the derivative operators. The abovementioned equations are solved using numerical analysis.

\section{Lightning Current Formulation}

There are many current functions with mathematical formulations that have been proposed to model the lightning behavior, such as 'Double Exponential', 'Jones Modification', 'Heidler', and 'Pulse' functions $[31,32]$. However, a proper function that can accurately model the lightning strike must have the following characteristics [33]:

- Shape the lightning waveform with a very good approximation, as the base shape described in [34].

- It must be able to provide the typical parameters of the lightning waveform, such as the maximum current peak, the maximum current slope, rise time, and settling time.

- No discontinuity should occur in the first and second derivatives of the current lightning model over time (especially at the instant $t=0$, due to magnetic and electric field calculations).

- The current lightning model must be differentiable, in order to calculate the electric and magnetic fields generated.

- It shouldn't be complicated to avoid appearing "Dirac delta function" or "doublet function" and their higher-order derivative through mathematical computations.

Therefore, the CIGRE model is used to represent the lightning current behavior in this paper. This single-phase model uses two portions as follows; one is to model the front-wave and the other for the tail-wave current model, where these two parts are fully continuous at the interconnect point.

\subsection{Front-Wave Model}

The front-wave model is expressed with Equation (12).

$$
\mathrm{I}(\mathrm{t})=\text { A.t }+ \text { B. } \mathrm{t}^{\mathrm{n}}
$$

where,

$$
\begin{aligned}
& A=\frac{1}{n-1}\left(0.9 n \times \frac{I_{m}}{t_{n}}-S_{m}\right) \\
& B=\frac{1}{t_{n}^{n}(n-1)}\left(S_{m} t_{n}-0.9 I_{m}\right)
\end{aligned}
$$

The above unknown variables are explained in (15)-(17).

$$
\begin{gathered}
\mathrm{n}=1+2\left(\mathrm{~s}_{\mathrm{N}}-1\right)\left(2+\frac{1}{\mathrm{~s}_{\mathrm{N}}}\right) \\
\mathrm{t}_{\mathrm{n}}=0.6 \mathrm{t}_{\mathrm{f}}\left(3 \frac{\mathrm{s}_{\mathrm{N}}^{2}}{1+\mathrm{s}_{\mathrm{N}}^{2}}\right) \\
\mathrm{s}_{\mathrm{N}}=\mathrm{S}_{\mathrm{m}} \times \frac{\mathrm{t}_{\mathrm{f}}}{\mathrm{I}_{\mathrm{m}}}
\end{gathered}
$$

$t_{f}$ and $S_{m}$ represent the front time of the waveform and the maximum slope, respectively.

\subsection{Tail-Wave Model}

The tail-wave lightning current is modeled using (18).

$$
I(t)=I_{1} e^{-\frac{\left(t-t_{n}\right)}{t_{1}}}-I_{2} e^{-\frac{\left(t-t_{n}\right)}{t_{2}}}
$$


In Equation (18), the coefficients are defined as:

$$
\begin{gathered}
\mathrm{t}_{1}=\frac{\mathrm{t}_{\mathrm{h}}-\mathrm{t}_{\mathrm{n}}}{\ln (2)} \\
\mathrm{t}_{2}=0.1 \frac{\mathrm{I}_{\mathrm{m}}}{\mathrm{S}_{\mathrm{m}}} \\
\mathrm{I}_{1}=\frac{\mathrm{t}_{1} \mathrm{t}_{2}}{\mathrm{t}_{1}-\mathrm{t}_{2}}\left(\mathrm{~S}_{\mathrm{m}}+0.9 \frac{\mathrm{I}_{\mathrm{m}}}{\mathrm{t}_{2}}\right) \\
\mathrm{I}_{2}=\frac{\mathrm{t}_{1} \mathrm{t}_{2}}{\mathrm{t}_{1}-\mathrm{t}_{2}}\left(\mathrm{~S}_{\mathrm{m}}+0.9 \frac{\mathrm{I}_{\mathrm{m}}}{\mathrm{t}_{1}}\right)
\end{gathered}
$$

In (19), $t_{h}$ is the time duration that the lightning current, reaches $50 \%$ of its maximum value. It is also worth noting that (18) is used when $t \geq t_{n}+t_{\text {start }}$. The current waveform described is shown in Figure 2.

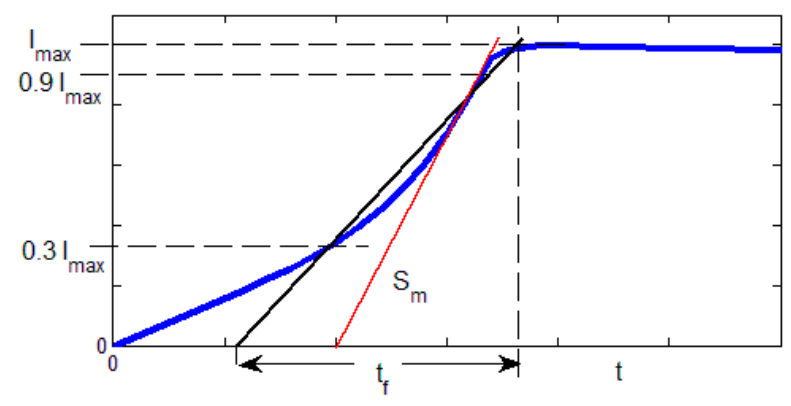

Figure 2. Lightning current waveform.

\section{Parameter Derivation}

The grounding system equivalent impedance spectrum, as extracted in (11), cannot be utilized straightly to ATP/EMTP software packages. Therefore, it is essential to convert this transfer function to the passive parameters within all high-frequency soil behaviors.

\subsection{Fast Relaxed Vector Fitting}

If the frequency response of a section of the power system is available as (23), formerly, it could be approximated with several finite rational functions, as in (24).

$$
\begin{gathered}
\mathrm{Z}(\mathrm{s})=\frac{\mathrm{a}_{0}+\mathrm{a}_{1} \mathrm{~s}+\ldots+\mathrm{a}_{\mathrm{N}} \mathrm{s}^{\mathrm{N}}}{\mathrm{b}_{0}+\mathrm{b}_{1} \mathrm{~s}+\ldots+\mathrm{b}_{\mathrm{N}} \mathrm{s}^{\mathrm{N}}} \\
\mathrm{Z}(\mathrm{s}) \cong \sum_{\mathrm{n}=1}^{\mathrm{N}} \frac{\mathrm{c}_{\mathrm{n}}}{\mathrm{s}-\mathrm{a}_{\mathrm{n}}}+\mathrm{d}+\mathrm{sh}
\end{gathered}
$$

where ' $s$ ' is the Laplace operator and $c_{n}$ and $a_{n}$ coefficients represent the residuals and fitted poles respectively. Moreover, $d$ and $h$ are real numbers which show the constant system impedance. The FRVF method will estimate all these coefficients with high accuracy to determine the rational functions. This approach includes two steps to approximate stable poles and proper residuals. In the first step, a set of stable preliminary poles is considered as an initial guess. Then, the matrix-fitting presented in $[35,36]$ will be used to obtain the deterministic real and complex conjugate fitted poles. At the second step, the residuals are defined by solving a set of linear equations as $A . x=B$ obtained from (24). However, the solutions attained from this approach are acceptable, but when they are compared with the real impedances, some of the resistors may get negative values. Therefore, a modification is needed to apply this criterion to the fitting process. As the matrix fitting is initiated with a set of stable 
preliminary poles, the round off errors might result in a high variance between the approximated poles and the real poles. Then, it could be solved by using the imaginary part of the poles, as in (26).

$$
\begin{gathered}
a_{n}=-p \pm j q \\
q=100 p
\end{gathered}
$$

Then, the low value imaginary parts of fitted poles are resolved, and the FRVF method diagram is shown in Figure 3.

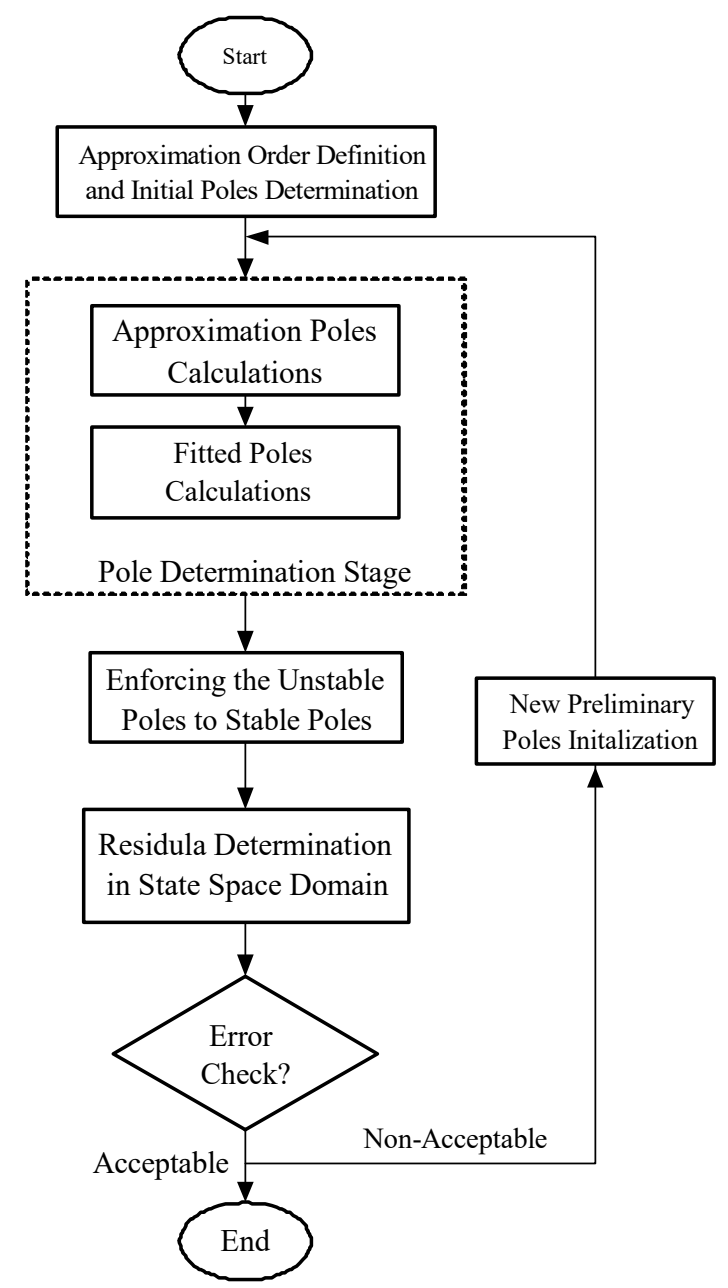

Figure 3. Fast relaxed vector fitting (FRVF) flowchart diagram.

\subsection{Soil Ionization}

To illustrate the behavior of high-frequency soil conductivity and relative soil permittivity, the Scott model is habitually considered [37,38]. To determine the mathematical formulation, Equations (27) and (28) should have been substituted with conventional soil conductivity and relative permittivity coefficients.

$$
\begin{aligned}
& \epsilon_{\mathrm{r}}(\mathrm{f})=5.491+0.946 \sigma_{0}-1.097 \mathrm{f}+0.069 \sigma_{0}^{2}-0.014 \mathrm{f} \sigma_{0}+0.067 \mathrm{f}^{2} \\
& \sigma(\mathrm{f})=0.028+1.098 \sigma_{0}-0.068 \mathrm{f}+0.036 \sigma_{0}^{2}-0.046 \mathrm{f} \sigma_{0}+0.018 \mathrm{f}^{2}
\end{aligned}
$$

However, there are many air-filled pores among the soil components; as shown in Figure 4, the soil model ionization has to be modified to represent the are transitions in air-filled pores, additionally. 
Therefore, the frequency-dependent consideration of soil conductivity and relative permittivity is not just enough. The model that could represent the full soil behavior is shown in Figure 5, that consists of a paralleled arc resistance and its capacitance series to the CIGRE resistance. The CIGRE model is mathematically formulated in (29) and (30).

$$
\begin{gathered}
\mathrm{R}_{\mathrm{g}}(I)=\frac{\mathrm{R}_{0}}{\sqrt{1+\frac{\mathrm{I}_{\text {lightning }}(\mathrm{t})}{\mathrm{I}_{\mathrm{g}}}}} \\
\mathrm{I}_{\mathrm{g}}=\frac{\mathrm{E}_{0}}{2 \pi \sigma_{\mathrm{g}} R_{0}^{2}}
\end{gathered}
$$

where $E_{0}$ is the critical electric field intensity of the soil, and $R_{0}$ is the ground resistance with low current at low frequency. Consequently, the capacitance of air-filled pores is presented in (31) [39].

$$
\mathrm{C}_{\mathrm{air}}=\frac{\rho_{0} \epsilon_{0}}{\mathrm{R}_{\mathrm{arc}}}
$$

where $R_{\text {arc }}$ is the arc resistance that created in the air-filled pores when the magnetic field could not be strengthened by the air. $R_{\text {arc }}$ is formulated with Browne's combined theory [40].

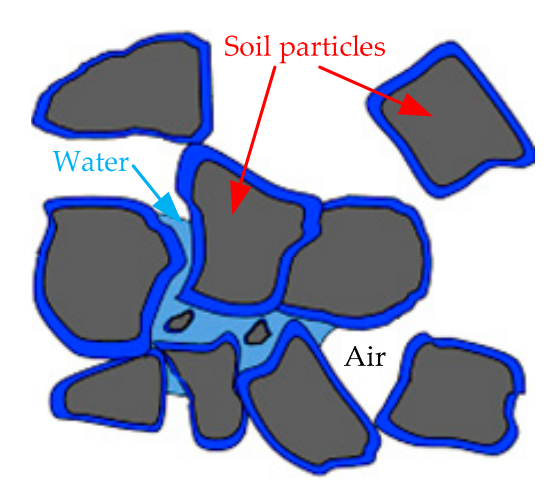

Figure 4. The main soil components.

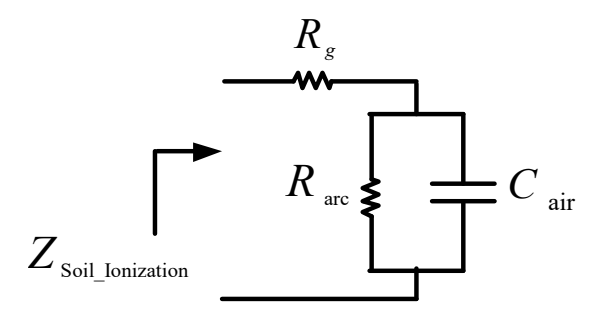

Figure 5. Complete model of soil ionization behavior.

\subsection{Circuit Based FRVF Model}

The basic circuit model as shown in Figure 6 is used to introduce the grounding grid high-frequency behaviors for many years. The passive parameters of resistance, inductance, and capacitance (RLC branch) are found in (32)-(35) [9-15].

$$
\begin{aligned}
\mathrm{R}_{\mathrm{c}} & =\frac{\rho}{2 \pi l}\left(\ln \left(\frac{4 l}{a}\right)-1\right) \\
\mathrm{Z}_{\mathrm{c}}=\sqrt{\frac{L}{\mathrm{C}}} & =\frac{1}{2 \pi}\left(\ln \left(\frac{4 l}{a}\right)-1\right) \sqrt{\frac{\mu_{0}}{\epsilon_{0}}} \\
\mathrm{~L}_{\mathrm{c}} & =2 l\left(\mathrm{Z}_{\mathrm{c}}-\mathrm{R}_{\mathrm{c}}\right)
\end{aligned}
$$




$$
\mathrm{R}_{\mathrm{s}}=\mathrm{Z}_{\mathrm{c}}-\mathrm{R}_{\mathrm{c}}
$$

where $a$ and $l$ represent the electrode diameter and length, respectively.

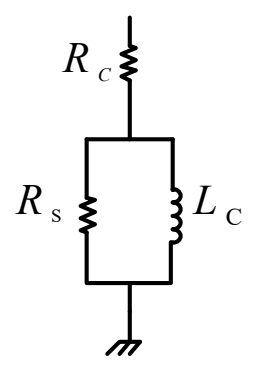

Figure 6. Conventional grounding system impedance model.

Currently, in order to evaluate the high-frequency behavior of the grounding system, along with the effect of soil ionization, Figure 7 shows the circuit-based diagram of the proposed strategy. As is observed, there are some series impedance branches with their real or complex conjugate poles; those are enforced to be stable. It means that the real part of all fitted poles will have a negative value to be located at the left side of the imaginary axis in the complex plane. In (24), however, all the $c_{n}$ and $a_{n}$ coefficients could be real or complex, but $d$ and $h$ are certainly real if they exist. The passive parameters of Figure 7 will be calculated with the following algorithm:
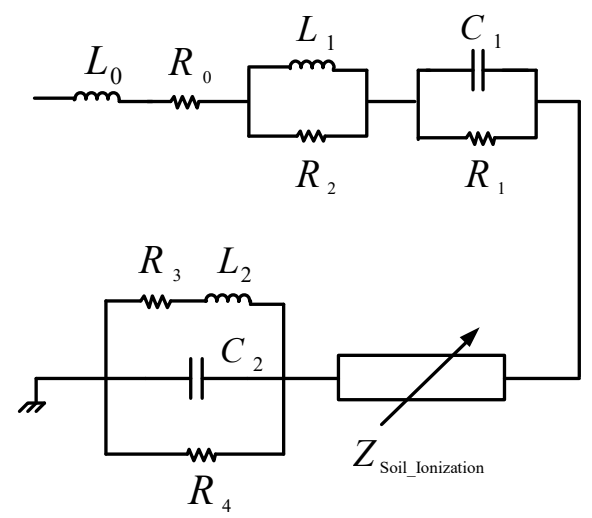

Figure 7. Proposed high frequency grounding system behavior considering soil ionization.

- The $d$ and $h$ coefficients represent the resistance and the inductance of grounding grid in the rest mode, which are determined by $R_{0}$ and $L_{0}$ respectively.

$$
\begin{aligned}
& R_{0}=d \\
& L_{0}=h
\end{aligned}
$$

- If the partial transfer function is defined as (37), then the poles are real and stable, thus we have:

$$
\begin{gathered}
Z_{i}(s)=\frac{c_{i}}{s+a_{i}}=\frac{\frac{1}{C_{1}}}{s+\frac{1}{R_{1} C_{1}}} \\
C_{1}=\frac{1}{c_{i}} \& R_{1}=\frac{a_{i}}{c_{i}}
\end{gathered}
$$

Other criteria must be applied to the parameter determination algorithm which prevent the resistance to be negative. 
- If $c_{j}$ in (39) is negative in transfer functions, it could be considered as (40). Then, while the poles are stable, this rational function is simplified to two partial ones. Therefore, the RL branch parameters will be computed with (41) and the newer rest impedance will be calculated as (42).

$$
\begin{gathered}
Z_{\mathrm{j}}(s)=\frac{c_{\mathrm{j}} s}{s+a_{\mathrm{j}}}=\frac{s \times R_{2}}{s+\frac{R_{2}}{L_{1}}} \\
Z_{\mathrm{j}}(s)=R_{2}+\frac{-\frac{R_{2}^{2}}{L 1}}{s+\frac{R_{2}}{L_{1}}} \\
L_{1}=-\frac{c_{\mathrm{j}}}{a_{\mathrm{j}}^{2}} \& R_{2}=-\frac{c_{\mathrm{j}}}{a_{\mathrm{j}}} \\
d^{\text {new }}=d^{\text {old }}-R_{2}>0
\end{gathered}
$$

- When the transfer function poles are complex conjugate, such as (43), they are calculated as (44)-(47).

$$
\begin{gathered}
Z_{k}(s)=\frac{c_{r}+j a_{r}}{s+\left(a_{r}+j a_{i}\right)}+\frac{c_{r}-j a_{r}}{s+\left(a_{r}-j a_{i}\right)} \\
C_{2}=\frac{1}{2 c_{r}} \\
L_{2}=\frac{2 c_{r}^{3}}{a_{i}^{2} \times c_{i}^{2}+a_{i}^{2} \times c_{r}^{2}} \\
R_{3}=\frac{2 c_{r}^{2}\left(a_{i} \times c_{i}+a_{r} \times c_{r}\right)}{a_{i}^{2} \times c_{i}^{2}+a_{i}^{2} \times c_{r}^{2}} \\
R_{4}=-\frac{2 c_{r}^{2}}{a_{i} \times c_{i}-a_{r} \times c_{r}}
\end{gathered}
$$

\section{Model Verification}

The proposed formulations and modeling strategy are examined on three different grounding systems, to evaluate their impedance magnitudes and phase angles. The proposed model is also compared and validated by the Grcev model, which is one of the most valuable structures in this study field. In the first scenario, a typical horizontal electrode is considered as a grounding system, and the frequency response of ground impedance is evaluated. In the second scenario, a high-capacitive capability earthling system will be analyzed, and the GPR will be checked. In the third scenario, we evaluate a real grounding grid, in which the effects of soil ionization parameters have been considered.

\subsection{Horizontal Electrode}

Figure 8 represents a horizontal grounding electrode that is excited by a $20 \mathrm{kA}$ lightning current. As could be observed, the grounding system frequency response has a nearly constant magnitude that occurs at low frequencies. However, since the impedance of the soil increases with increasing the frequency, the frequency response will similarly be proportional to those variations. For low-soil resistivity (100 to $1000 \Omega \cdot \mathrm{m}$ ), the impedance magnitude increases at high frequencies, which can be justified by inductive behavior modeling of the structure, as shown in Figure 9. Figure 10 represents the phase angles correspondingly that relies on inductive behavior of grounding grids, due to their 
reachability to $90^{\circ}$ mostly. As the soil resistivity increases, impedance amplitude growth begins at lower frequencies. As a result, in more fertile soils, the frequency response angle becomes faster to achieve to $90^{\circ}$.

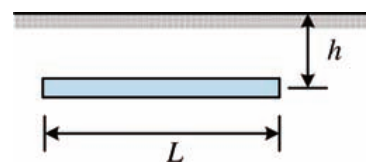

Figure 8. A typical horizontal electrode as a grounding grid.

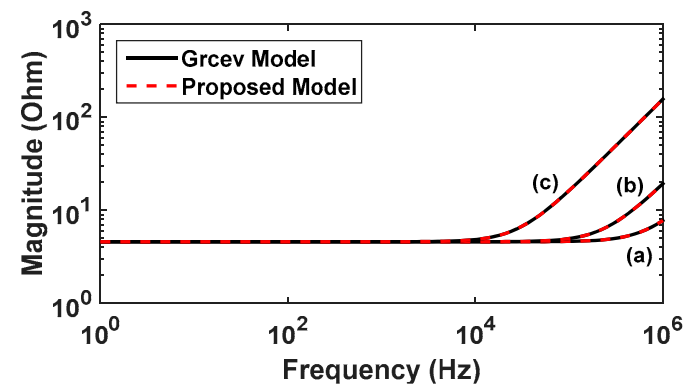

Figure 9. Impedance magnitude of a typical horizontal electrode; (a) $\rho=100 \Omega \cdot m$, (b) $\rho=300 \Omega \cdot m$, (c) $\rho=1000 \Omega \cdot \mathrm{m}$.

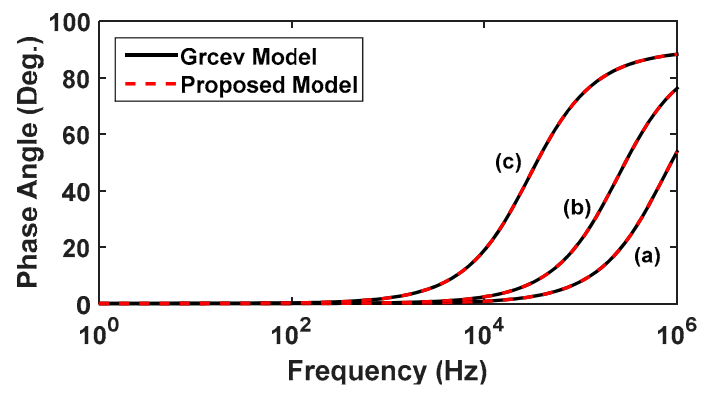

Figure 10. Phase angle of a typical horizontal electrode; (a) $\rho=100 \Omega \cdot m,(b) \rho=300 \Omega \cdot m,(c) \rho=1000 \Omega \cdot m$.

In the investigation of the optimal length of the horizontal electrodes of the grounding system, the impedance frequency response is calculated for a length of $2 \mathrm{~m}$ to $100 \mathrm{~m}$ at the same condition. When the same current amplitude is injected into one of the two ends of the electrode, the impedance changes as the soil resistivity changes, which is shown in Figure 11. This plot diagram, which is drawn at a frequency of $50 \mathrm{~Hz}$, reflects the electrode impedance, decreasing since the length is increased. However, as the frequency of the injected current increases, the impedance reduction will stop after a while, and its magnitude will be fixed at a definite constant value. The length of the electrode, when the impedance amplitude begins to be constant, is called the optimal length, and should be used in the grounding grid designs. These results indicate that the lower the frequency, the effective length will be less for a specific reduction. For example, at a frequency of $1 \mathrm{kHz}$, the effective length for a specific resistance of 10,000 ohms-m is about $1000 \mathrm{~m}$ long. However, this effective length can be reduced to $40 \mathrm{~m}$ in the soil resistivity of $10 \mathrm{ohms}$. The point that was previously expected is that, as the frequency increases, the effective length of the horizontal electrodes decreases. 


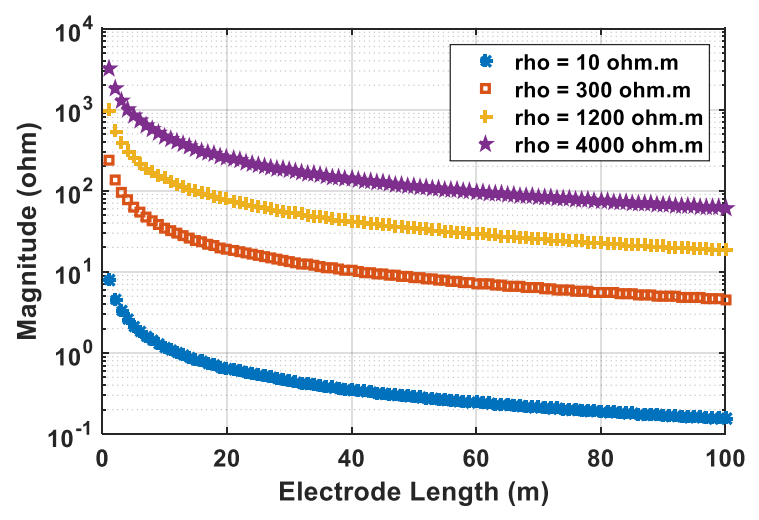

Figure 11. Grounding system effective length.

\subsection{A Simple Grounding Grid}

Figure 12 shows a relatively simple grounding system that consists of several horizontal and vertical electrodes. The evaluation of this grounding system as a second case study is due to the revision of soil capacitive behavior. The Earth capacitive behavior in the theory of the transmission line is fully justified [17].

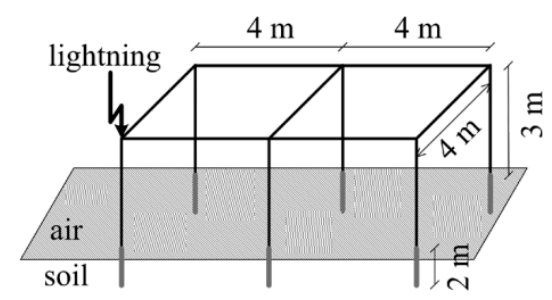

Figure 12. A Simple Grounding Grid.

Currently, the frequency response diagrams of the grounding grid represented in Figures 13 and 14, show that initially, at low frequencies, the system is considered to be capacitive, and the ground impedance is high due to this capacitive property. The phase angle diagram of ground frequency response is also distributed between $-90^{\circ}$ to $0^{\circ}$. As the frequency increases, the grounding system decreases the capacitive property, and enhances the inductive characteristics. This reduces the impedance magnitude, which pushes the phase angle to zero. Then, the higher the frequency, the more indicative of its inductive property, thus, the impedance magnitude of the grounding system will increase. As expected, the frequency response phase angle will reach around 90 degrees.

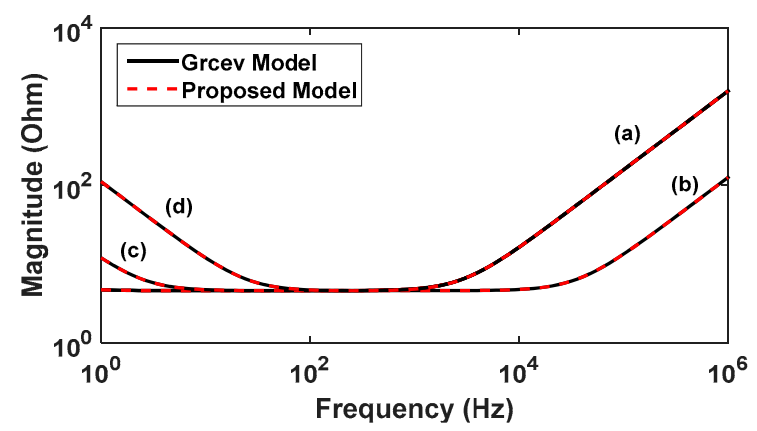

Figure 13. Impedance magnitude of a simple grounding grid; (a) $\rho=100 \Omega \cdot m$, (b) $\rho=300 \Omega \cdot m$, (c) $\rho=1000 \Omega \cdot m,(d) \rho=1800 \Omega \cdot m$. 


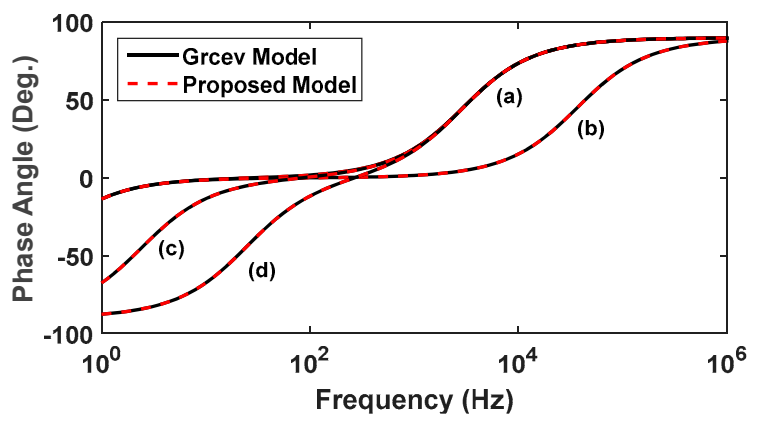

Figure 14. Phase angle of a simple grounding grid; (a) $\rho=100 \Omega \cdot m$, (b) $\rho=300 \Omega \cdot m$, (c) $\rho=1000 \Omega \cdot m$, (d) $\rho=1800 \Omega \cdot m$.

As explained in [18], the Grcev model uses the electromagnetic formulation to derive the semi-precise equivalent circuit of horizontal and vertical model. Since this model is approximately matched with the real data up to one $\mathrm{MHz}$, we use a comparison of proposed approach to Grcev model it this range of frequency. The formulations founded in [18], despite the accurate solution, are hired, to derive the equivalent circuit of each horizontal and vertical electrodes, individually, while the proposed approach presented here uses only one equivalent circuit for all grounding grid. Therefore, our strategy can be implemented much more easily than the Grcev model.

The ground potential rise (GPR), or Earth potential rise, is a phenomenon that occurs when large amounts of electricity enter the earth. This is typically caused when substations or high-voltage towers fault, or when lightning strikes occur. When currents of large magnitude enter the earth from a grounding system, not only will the grounding system rise in electrical potential, but so will the surrounding soil as well. The voltages produced by a GPR or Earth potential rise event can be hazardous to both personnel and equipment. As described earlier, the soil has resistance known as soil resistivity, which will allow an electrical potential gradient or voltage drop to occur along the path of the fault current in the soil.

The resulting potential differences will cause currents to flow into any and all nearby grounded conductive bodies, including concrete, pipes, copper wires and people [25-29]. The GPR calculated in different soil resistivity is visible in Figure 15. As can be seen, the CIGRE function as an excitation source with a $400 \mathrm{ohm}$ lightning channel is multiplied to the proposed impedance diagram, and GPR is calculated compared to the ideal node within zero potential relatives. The higher the soil resistance, the higher the GPR production will be.

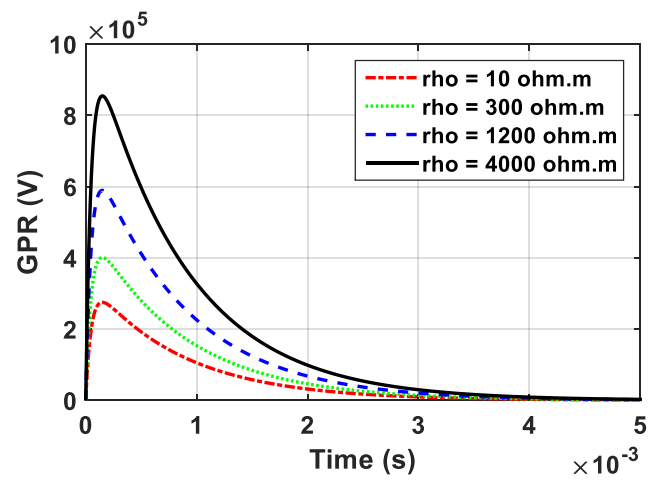

Figure 15. GPR of a simple grounding grid.

\subsection{A Complicated Grounding Grid}

The grounding system under consideration in this section, as shown in Figure 16, includes several circular electrodes, a number of vertical rods, and numerous horizontal electrodes that are interconnected. Their apparent characteristics, in terms of length and positioning, have been adjusted 
so that the grounding system can be used as a wind turbine system or a high voltage electric tower grid. Thus, the effect of soil ionization dependence on frequency is also evaluated, and the proposed modeling effect is compared with the frequency-independent conditions.

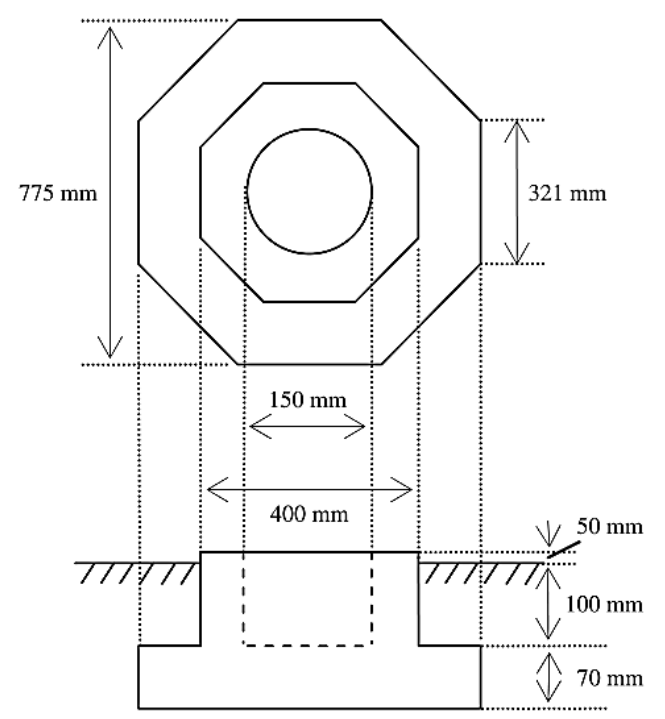

Figure 16. View of the grounding grid under study.

Figure 17 show the impedance magnitude and its phase angle in several soil resistivity with the effect of frequency-dependent soil ionization. As is observed, the proposed method is well suited to the data extracted from the CDEGS software, which suggests its high accuracy and effectiveness. Conductivity and permittivity are two important electrical properties of soil. Several factors, such as soil compaction, temperature, moisture, and grain size, affect soil conductivity and permittivity. Soil ionization occurs because of the electric field enhancement in soil when subjected to high impulse current discharge, which in turn causes the electric breakdown of air voids enclosed between soil particles. The air breakdown causes current to flow in the voids, and this is usually in the form of an arc. The growth of the arc within the whole soil structure is further described as containing many discrete breakdown channels and branching in nature. Soil medium is a mixture of fragmented mineral materials, organic matter, and gases. The size and distribution of both the soil particles and the air-filled pores are not uniform. To facilitate the computations for engineering purposes, the soil can be represented by an ordered network of soil particles and air voids, as shown in Figure 4. The impulse current mostly flows through the soil particles when there is no ionization, because of the much lower soil resistance. Therefore, the soil ionization phenomena are very important to be considered. If soil ionization is assumed to be frequency independent, Figure 18 are obtained, and the outcomes of the proposed algorithm will still match the data extracted from the CDEGS finite element software. It can be concluded that the impedance of the typical grounding grids buried in soil changes as a function of frequency. The characteristic of the grounding electrode is assessed depending on the soil resistivity. The characteristics of the grounding electrode in low resistivity and high-resistivity soils are dominantly capacitive and inductive, respectively. In both cases of frequency-independent and frequency-dependent, the magnitude and phase angle in all figures varied correspondingly as the frequency increases. In the case of frequency-dependent, the increase of magnitude is a bit higher than the frequency-independent case. On the contrary, the phase angle, in the case of frequency-dependent, increases, but not in the same way as the angle in the case of frequency-independent. There are some spikes in frequency dependent diagrams which rely on the evacuation of the magnetic field at some susceptible points in the soil. 


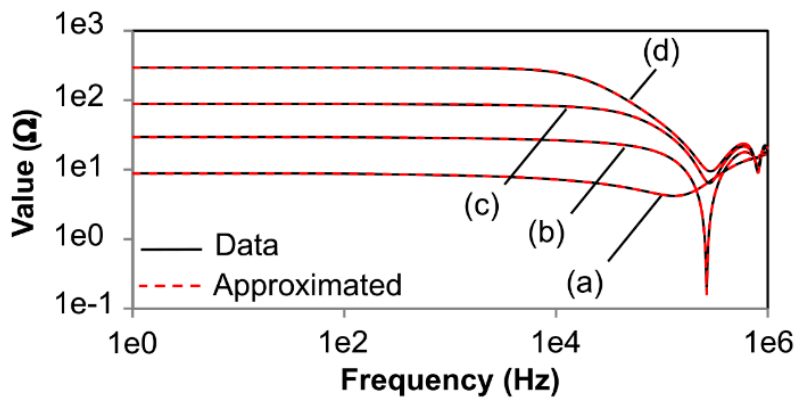

(a)

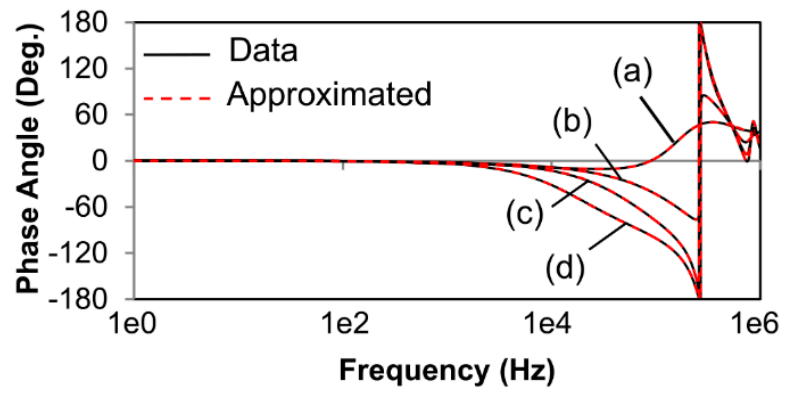

(b)

Figure 17. Impedance characteristics of a complicated grounding grid considering frequency dependent soil ionization; (a) impedance magnitude, (b) impedance phase angle. (a) $\rho=100 \Omega \cdot m$, (b) $\rho=300 \Omega \cdot m$, (c) $\rho=2000 \Omega \cdot m,(d) \rho=8000 \Omega \cdot m$.

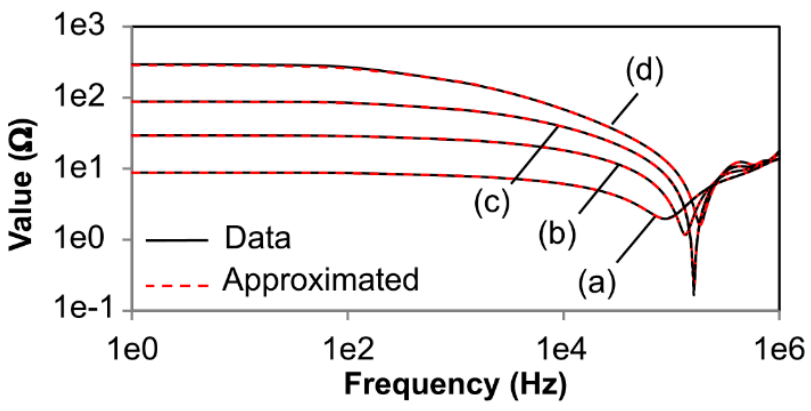

(a)

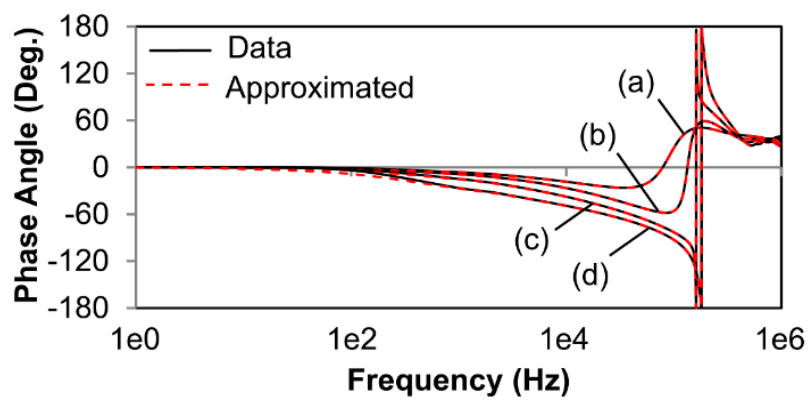

(b)

Figure 18. Impedance characteristics of a complicated grounding grid, considering frequency dependent soil ionization; (a) impedance magnitude, (b) impedance phase angle. (a) $\rho=100 \Omega \cdot m$, (b) $\rho=300 \Omega \cdot m$, (c) $\rho=2000 \Omega \cdot m,(d) \rho=8000 \Omega \cdot m$.

\section{Conclusions}

When the high-frequency lightning strokes collide to the ground as a shock wave and excite it, the Earth high-frequency components emerge from the ground, causing soil ionization. Afterwards, 
the soil particles properties cause the non-linearization of the transient state of buried grounding grid under the soil. If the grounding system is buried in multi-layered soils with different special resistivity through different geometries, such as cylindrical or spherical soils components, the modeling of its electrodes to analyze power networks in software packages is practically impossible. This paper presents a novel method to evaluate all these phenomena, in order to analyze the transient state of electromagnetic waves due to the lightning strikes. Considering this technique, each grounding grid can be modeled and appraised using a simple multi-circuit model, with low-order characteristic approximation equations in a wide frequency range. Another feature of the proposed strategy is the high accuracy compared with some existing methods. Regarding those approaches, there is no possibility to model and predict the wave propagation delay. In addition, the calculation speed is more accurate than that of the electromagnetic waves theory. On the other hand, one can analyze the most complex grounding systems by any conventional processor. However, in many previous methods, parallel processors are required with very high power, due to the high-usage of current and voltage dependent sources. Finally, the results and output diagrams obtained from the proposed technique are validated with the Grcev formulation. Table 1 compares all existing approaches.

Table 1. Prototype specifications. PPF: passive power filter.

\begin{tabular}{|c|c|c|c|c|c|c|}
\hline Approaches & Complexity & $\begin{array}{l}\text { Soil Ionization and } \\
\text { Wave Delay }\end{array}$ & Realization & Processor & $\begin{array}{c}\text { EMTP } \\
\text { Implementation }\end{array}$ & $\begin{array}{l}\text { Performance } \\
\text { and Accuracy }\end{array}$ \\
\hline $\begin{array}{l}\text { Electromagnetic } \\
\text { Theory }\end{array}$ & Complicated & $\begin{array}{l}\text { Hard to model soil } \\
\text { ionization, enable to } \\
\text { evaluate the } \\
\text { propagation in } \\
\text { lossy conductors }\end{array}$ & Hard & $\begin{array}{l}\text { Powerful, with } \\
\text { great } \\
\text { calculation time }\end{array}$ & Hard to obtain & $\begin{array}{c}\mathrm{CT}<60 \mathrm{~s} \\
\mathrm{EP}<8 \mathrm{~s}\end{array}$ \\
\hline Circuit Theory & Simple & $\begin{array}{l}\text { Relatively simple to } \\
\text { model soil } \\
\text { ionization, unable to } \\
\text { evaluate the } \\
\text { propagation in } \\
\text { lossy conductors }\end{array}$ & Simple & $\begin{array}{l}\text { Usual, with low } \\
\text { calculation time }\end{array}$ & Simple & $\begin{array}{c}\mathrm{CT}<120 \mathrm{~s} \\
\mathrm{EP}<16 \mathrm{~s}\end{array}$ \\
\hline Hybrid Approaches & $\begin{array}{l}\text { Relatively } \\
\text { complicated }\end{array}$ & $\begin{array}{l}\text { Hard to model soil } \\
\text { ionization, enable to } \\
\text { evaluate the } \\
\text { propagation in } \\
\text { lossy conductors }\end{array}$ & Relatively hard & $\begin{array}{l}\text { Usual, with } \\
\text { relatively low } \\
\text { calculation time }\end{array}$ & $\begin{array}{l}\text { Relatively hard } \\
\text { to obtain }\end{array}$ & $\begin{array}{l}\mathrm{CT}<90 \mathrm{~s} \\
\mathrm{EP}<12 \mathrm{~s}\end{array}$ \\
\hline $\begin{array}{c}\text { Transmission Line } \\
\text { Model }\end{array}$ & Simple & $\begin{array}{l}\text { Hard to model soil } \\
\text { ionization, enable to } \\
\text { evaluate the } \\
\text { propagation in } \\
\text { lossy conductors }\end{array}$ & Simple & $\begin{array}{l}\text { Usual, with low } \\
\text { calculation time }\end{array}$ & Relatively simple & $\begin{array}{l}\mathrm{CT}<90 \mathrm{~s} \\
\mathrm{EP}<12 \mathrm{~s}\end{array}$ \\
\hline Proposed Strategy & $\begin{array}{l}\text { Simple and } \\
\text { based on } \\
\text { rational } \\
\text { functions }\end{array}$ & $\begin{array}{l}\text { Simple to model soil } \\
\text { ionization, enable to } \\
\text { evaluate the } \\
\text { propagation in } \\
\text { lossy conductors }\end{array}$ & Simple & $\begin{array}{l}\text { Usual, with low } \\
\text { calculation time }\end{array}$ & Very simple & $\begin{array}{l}\mathrm{CT}<30 \mathrm{~s} \\
\mathrm{EP}<4 \mathrm{~s}\end{array}$ \\
\hline
\end{tabular}

Where CT stands for computation time and EP represents the error percentage, since we have:

$$
E P=|| \text { data }|-| \text { fitted } \| \times 100
$$

Author Contributions: M.F.: writing the manuscript and simulation; M.M.: conceptualization and simulation; E.M.G.R.: review, editing and funding. All authors have read and agreed to the published version of the manuscript.

Funding: This research received no external funding.

Conflicts of Interest: The authors declare no conflict of interest.

\section{References}

1. Liu, X.; Ge, T. An Efficient Method for Calculating the Lightning Electromagnetic Field Over Perfectly Conducting Ground. Appl. Sci. 2020, 10, 4263. [CrossRef]

2. Qamar, A.; Ul Haq, I.; Alhaisoni, M.; Qadri, N.N. Detecting Grounding Grid Orientation: Transient Electromagnetic Approach. Appl. Sci. 2019, 9, 5270. [CrossRef] 
3. Cooper, M.A.; Holle, R.L. Lightning Protection. In Reducing Lightning Injuries Worldwide; Springer: Cham, Switzerland, 2019; pp. 165-177.

4. Meliopoulis, A.S. Power System Grounding and Transients: An Introduction; Routledge: Abingdon, UK, 2017; Volume 50.

5. Muzzammel, R.; Raza, A.; Hussain, M.R.; Abbas, G.; Ahmed, I.; Qayyum, M.; Rasool, M.A.; Khaleel, M.A. MT-HVdc systems fault classification and location methods based on traveling and non-traveling waves-A comprehensive review. Appl. Sci. 2019, 9, 4760. [CrossRef]

6. Zhang, X. A circuit approach to the calculation of lightning transients in cage-like multiconductor systems. Int. J. Electr. Eng. Educ. 2010, 47, 213-222. [CrossRef]

7. Mentre, F.E.; Grcev, L. EMTP-based model for grounding system analysis. IEEE Trans. Power Deliv. 1994, 9 , 1838-1849. [CrossRef]

8. Heimbach, M.; Grcev, L.D. Grounding system analysis in transients programs applying electromagnetic field approach. IEEE Trans. Power Deliv. 1997, 12, 186-193. [CrossRef]

9. Mahmoudian, M.; Gholami, A.; Sadrpour, S.M. Perfect Modelling of Grounding Systems to Study Electromagnetic Transients Using Vector Fitting Method. Majlesi J. Electr. Eng. 2012, 6, 1-6.

10. Mahmoudian, M.; Gholami, A.; Sadrpour, S.M.; Arekhi, A. Transient Analysis of Grounding System in a Wind Farm Based on Antenna Theory Using Fast Relaxed Vector Fitting Method. PSC 2014, 1-7.

11. Fu, Z.; Wang, X.; Wang, Q.; Xu, X.; Fu, N.; Qin, S. Advances and challenges of corrosion and topology detection of grounding grid. Appl. Sci. 2019, 9, 2290. [CrossRef]

12. Chen, H.; Du, Y. Lightning grounding grid model considering both the frequency-dependent behavior and ionization phenomenon. IEEE Trans. Electromagn. Compat. 2018, 61, 157-165. [CrossRef]

13. De Seixas, C.M.; Kurokawa, S. Using circuit elements to represent the distributed parameters of a grounding system under lightning strokes. Electr. Power Syst. Res. 2019, 172, 213-220. [CrossRef]

14. Celli, G.; Ghiani, E.; Pilo, F. Behaviour of grounding systems: A quasi-static EMTP model and its validation. Electr. Power Syst. Res. 2012, 85, 24-29. [CrossRef]

15. Ramamoorty, M.; Narayanan, M.B.; Parameswaran, S.; Mukhedkar, D. Transient performance of grounding grids. IEEE Trans. Power Deliv. 1989, 4, 2053-2059. [CrossRef]

16. Theethayi, N.; Baba, Y.; Rachidi, F.; Thottappillil, R. On the choice between transmission line equations and full-wave Maxwell's equations for transient analysis of buried wires. IEEE Trans. Electromagn. Compat. 2008, 50, 347-357. [CrossRef]

17. Andolfato, R.; Bernardi, L.; Fellin, L. Aerial and grounding system analysis by the shifting complex images method. IEEE Trans. Power Deliv. 2000, 15, 1001-1009. [CrossRef]

18. Grcev, L.D.; Kuhar, A.; Arnautovski-Toseva, V.; Markovski, B. Evaluation of high-frequency circuit models for horizontal and vertical grounding electrodes. IEEE Trans. Power Deliv. 2018, 33, 3065-3074. [CrossRef]

19. Grcev, L. Impulse efficiency of ground electrodes. IEEE Trans. Power Deliv. 2008, 24, 441-451. [CrossRef]

20. Grcev, L.; Dawalibi, F. An electromagnetic model for transients in grounding systems. IEEE Trans. Power Deliv. 1990, 5, 1773-1781. [CrossRef]

21. Plonka, G.; Potts, D.; Steidl, G.; Tasche, M. Numerical Fourier Analysis; Springer International Publishing: Cham, Switzerland, 2018.

22. Rothwell, E.J.; Cloud, M.J. Electromagnetics; CRC Press: Boca Raton, FL, USA, 2018.

23. Garma, T.; Šesnić, S.; Poljak, D.; Matković, A. Impulse impedance of the horizontal grounding electrode: Comparison of the theoretical antenna model approach and experimental analysis. J. ElEctromagn. Waves Appl. 2017, 31, 769-780. [CrossRef]

24. Poljak, D. Frequency Domain and Time Domain Response of the Horizontal Grounding Electrode Using the Antenna Theory Approach. In Engineering Mathematics I.; Springer: Cham, Switzerland, 2016; pp. 1-12.

25. Grcev, L.; Kuhar, A.; Markovski, B.; Arnautovski-Toseva, V. Generalized Network Model for Energization of Grounding Electrodes. IEEE Trans. Electromagn. Compat. 2018, 60, 1082-1090. [CrossRef]

26. He, J.; Zhang, B. Progress in lightning impulse characteristics of grounding electrodes with soil ionization. IEEE Trans. Ind. Appl. 2015, 51, 4924-4933. [CrossRef]

27. Gazzana, D.S.; Tronchoni, A.B.; Leborgne, R.C.; Bretas, A.S.; Thomas, D.W.; Christopoulos, C. An improved soil ionization representation to numerical simulation of impulsive grounding systems. IEEE Trans. Magn. 2017, 54, 1-4. [CrossRef] 
28. Li, Z.X.; Rao, S.W. Transient lightning response of grounding grids in a horizontal, multilayered soil model that considers soil ionization effects with time-domain quasi-static complex images. Int. J. Numer. Model. Electron. Netw. Dev. Fields 2019, 32, e2463. [CrossRef]

29. Dorić, V.; Poljak, D.; Roje, V. Transient analysis of the grounding electrode based on the wire antenna theory. Eng. Anal. Bound. Elem. 2004, 28, 801-807. [CrossRef]

30. Poljak, D.; Cerdic, D.; Doric, V.; Peratta, A.; Roje, V.; Brebbia, C.A. Boundary element modeling of complex grounding systems: Study on current distribution. In Boundary Elemens and Other Mesh Reduction Methods; BEM: Columbia, SC, USA, 2010; Volume 32, pp. 123-132.

31. Elrodesly, K.; Hussein, A.M. CN tower lightning return-stroke current simulation. J. Light. Res. 2012, 4, 60-70. [CrossRef]

32. Nucci, C.A.; Diendorfer, G.; Uman, M.A.; Rachidi, F.; Ianoz, M.; Mazzetti, C. Lightning return stroke current models with specified channel-base current: A review and comparison. J. Geophys. Res. Atmos. 1990, 95, 20395-20408. [CrossRef]

33. Pavanello, D.; Rachidi, F.; Rakov, V.A.; Nucci, C.A.; Bermudez, J.L. Return stroke current profiles and electromagnetic fields associated with lightning strikes to tall towers: Comparison of engineering models. J. Electrost. 2007, 65, 316-321. [CrossRef]

34. Pavlovic, D.; Milovanovic, G.; Cvetic, J. Calculation of the channel discharge function for the generalized lightning traveling current source return stroke model. Filomat 2019, 32, 6937-6951. [CrossRef]

35. Semlyen, A.; Gustavsen, B. Vector fitting by pole relocation for the state equation approximation of nonrational transfer matrices. Circuits Syst. Signal Process. 2000, 19, 549-566. [CrossRef]

36. Gustavsen, B. Improving the pole relocating properties of vector fitting. IEEE Trans. Power Deliv. 2006, 21, 1587-1592. [CrossRef]

37. Mokhtari, M.; Abdul-Malek, Z.; Wooi, C.L. Integration of frequency dependent soil electrical properties in grounding electrode circuit model. Int. J. Electr. Comput. Eng. 2016, 6, 792.

38. Robinson, D.A.; Abdu, H.; Lebron, I.; Jones, S.B. Imaging of hill-slope soil moisture wetting patterns in a semi-arid oak savanna catchment using time-lapse electromagnetic induction. J. Hydrol. 2012, 416, 39-49. [CrossRef]

39. Kristensson, G. Scattering of electromagnetic waves by obstacles. Inst. Eng. Technol. 2016. Available online: https://digital-library.theiet.org/content/books/ew/sbew524e (accessed on 15 June 2020).

40. Garzon, R.D. High Voltage Circuit Breakers: Design and Applications; CRC Press: Boca Raton, FL, USA, 2002. 